\title{
DOS GÊNEROS TEXTUAIS UTILIZADOS NA FORMAÇÃO DO PROFESSOR DE BIOLOGIA
}

\section{(On textual genres used in Biology teacher trainning development)}

\author{
Odisséa Boaventura de OliveIrA \\ (Universidade Federal do Paraná) \\ Silvia Luiza Frateschi Trivelato \\ (Universidade de São Paulo - USP)
}

Resumo: Problematiza-se nesta pesquisa os gêneros relatório e artigo científico escritos por 4 estudantes- estagiários na disciplina Prática de Ensino de Biologia, tomando-se as funções enunciativas locutor, enunciador e autor, conforme explicitadas por Orlandi (2003). Considera-se o locutor aquele que se representa como 'eu' no discurso; o enunciador é o que representa as 'perspectivas que o eu assume' no discurso e autor, quando se assume enquanto 'produtor' da linguagem, portanto afetado pelo contato com o social e suas coerções. A análise dos textos escritos aponta que tais gêneros não contribuíram expressivamente para manifestações subjetivas do ser e estar professor, por conta disso propõe-se a escrita de textos que levem o autor a se identificar com aquilo que escreve deixando ali suas marcas subjetivas.

Palavras-chave: Relatório; Artigo científico; Estágio supervisionado.

Abstract: This paper discusses reports and articles produced by 4 students in a Biology training course in teacher training course. It analises the enunciative functions of the speaker, the enunciator, and author, according to Orlandi (2003). The Speaker is represented as "I"; the enunciator represents the "perspectives that the I take on" and the author, when the student takes the role of the "producer" of the language, therefore affected by the contact with the social context and its coercions. The analysis of the texts shows that such genres did not contribute expressively to subjective manifestations of the self and being of the teacher. We therefore suggest the writer leaves identity marks in his writting.

Key-words: Report; Article; Supervised internship.

\section{INTRODUÇÃO}

Nossa preocupação com os gêneros escritos utilizados nas instituições educacionais advém de pesquisa anterior, na qual observamos que a escrita 
de cartas, diários, pequenas estórias, em aulas de Ciências do Ensino Fundamental possibilitou ao aluno assumir-se como autor, ou seja, a emancipar-se da repetição e da cópia em que estava inscrito, passando a elaborar sentidos próprios. $\mathrm{Na}$ investigação atual, analisamos a importância dos gêneros relatório e artigo, escritos por estudantes do curso de Ciências Biológicas na disciplina Prática de Ensino e Estágio Supervisionado, na promoção da autoria. Nossa opção por ambos justifica-se por constituírem modalidades de escrita acadêmica, familiares aos licenciandos.

Para isso, julgamos que a escrita na formação docente pode ser uma ferramenta que contribui para a manifestação de sentimentos, expectativas e identificações profissionais do futuro professor, ou como define Andrade (2004, p. 119), a escrita como "um caminho formador favorável à constituição de sujeitos autores, que possam autonomamente buscar os conhecimentos (...)”. Para isso acreditamos na importância de proporcionar aos licenciandos-estagiários a oportunidade de produzir determinados gêneros textuais que possibilitem a reflexão sobre suas ações, a formalização de saberes necessários à prática pedagógica, uma revisão crítica de sua formação e, por fim, produzir-se como professor.

Adotamos nesta pesquisa conceitos da Análise de Discurso (AD) de linha francesa, apresentados nas obras de Eni Orlandi. Um deles, a linguagem como "espaço de exterioridade" no qual se desenvolve uma rede de lugares distintos. Em suas diferentes manifestações, nas suas diferentes naturezas (verbal e não verbal), ela deve ser pensada não a partir dos conteúdos que veicula, mas como "matéria estruturante dos sujeitos". A linguagem, desse modo, tem papel constitutivo, demandando sempre uma tomada de posição.

Outro conceito, o de autoria, será entendido como um gesto de deslocamento do "já dito" que compõe a memória de cada um e de seus efeitos, uma vez que um autor, segundo Orlandi, se faz na tensão entre a paráfrase e a polissemia, o mesmo e o diferente, entre o novo e o inédito, assumindo o papel de intérprete e de desconstrutor do já estabelecido.

Para Orlandi (2000) o sujeito-escritor pode assumir três funções enunciativas em seu texto: a de locutor, aquele que se representa como 'eu' no discurso; a de enunciador, quando representa as 'perspectivas que o eu assume' no discurso e, finalmente, autor, quando se assume enquanto 'produtor' da linguagem, a despeito de sua inserção no social e suas coer- 
ções. Por exemplo, num texto sobre avaliação o locutor é definido como o sujeito que está falando, o que assina o texto, seja na condição de aluno ou de professor. $\mathrm{O}$ enunciador é a perspectiva assumida no texto, que pode ou não coincidir com a do locutor, logo ele pode falar como professor ou como aluno. Já na função autor, é preciso que o sujeito assuma uma posição.

Em sua visão, Orlandi esclarece que num texto o sujeito está sempre dividido nessas várias posições, a de locutor, de enunciador e de autor. Para se constituir como autor é preciso que assuma uma posição sócio-histórica, ou seja, marque discursivamente a sua inserção na cultura, identificando-se como indivíduo. Assim, autor é o sujeito que tendo o domínio de certos mecanismos discursivos, utiliza-os na ordem social em que está inserido. Age não apenas como o sujeito que fala de si ou de um objeto, mas enuncia a partir de um outro e próprio lugar as perspectivas que constrói.

Sendo a autoria uma função determinada pelas exigências de coerência, não contradição, responsabilidade, originalidade etc, é uma noção interessante para se observar a relação entre sujeito e discurso, particularmente a ação do discurso sobre o sujeito. No autor fica visível suas intenções, objetivos, direcionamento discursivo, na medida em que se coloca na origem de seu dizer. Há na autoria relação com a interpretação. Ademais, como autor o sujeito reconhece uma exterioridade à qual ele deve se referir - o interlocutor - mas também se remete à sua interioridade - o interdiscurso, ou seja, o já dito que disponibiliza dizeres, o que já foi falado em outros lugares, formulações já feitas, mas esquecidas. Os sentidos se constroem sobre essa memória.

Ainda que Orlandi (2003) aponte não ter interesse pela organização do texto e sim pelo discurso que o significa, consideração que secundariza a constituição de gêneros, optamos por explorar a textualização por concordar que o texto representa a materialidade do discurso e que suas características linguísticas são importantes para nosso estudo, uma vez que centramos esta análise na escrita de dois gêneros bastante comuns no meio acadêmico. Para Maingueneau (1991 apud Furlanetto, 2005), as possibilidades enunciativas do autor tomam como critério o institucional, ou seja, são as instituições que ditam o que pode ser dito, para quem e em que circunstâncias. Essa ideia nos faz crer que já existe uma ritualização incorporada pelos estudantes universitários dos modos de organizar um relatório e um artigo científico. 
Entendemos, então que um texto materializa-se num gênero pela correlação entre elementos de sua organização (o linguístico) e as condições de produção (o social), o que significa pensar em constituição de sentido. Portanto, a escrita normatizada por determinado gênero implica em coerções, ou melhor, expressa certa configuração pré fixada por uma comunidade discursiva. Assim, o ponto de partida para a caracterização do gênero (cartas, panfletos, artigos científico, relatórios de estágio etc) são os lugares enunciativos do sujeito (de onde se fala) que para se significar configurará seu discurso ao dispositivo verbal e institucional, pois "para cada gênero há uma expectativa (normas ou rotinas, deveres e direitos) para locutores e destinatários" (Furlanetto, 2005, p.269).

Dessa forma, no presente artigo investigamos nos textos escritos pelos licenciandos do Curso de Ciências Biológicas, além da forma como eles se referem a si mesmos no texto, as manifestações de subjetividade, a estrutura do texto e a incorporação de aspectos teóricos que se relacionem à prática docente. Amiúde, interessa-nos também a forma como eles se posicionaram nos relatórios e artigos, como se referiram a si mesmos, ou se falam de um lugar aparentemente sem sujeito. Isso dá margem para compreendermos a contribuição da escrita destes gêneros na formação de professores. Para tanto, analisaremos as funções enunciativas que o sujeito pode assumir ao escrever seu texto, ou seja, como locutor, enunciador ou autor.

\section{FundAMENTAÇÃO TEÓRICA}

Aprofundamos nessa seção os conceitos de locutor, de enunciador e de autor. Complementando o que dissemos, o locutor é aquele que se representa como "eu" no discurso, é quem assina o texto. Julgamos importante observar essa função nos textos escritos pelos licenciandos para identificar suas origens enunciativas, como eles se auto-referem.

Esclarecemos que não estamos adotando, como propõe Benveniste (Coracini, 1991) determinar a subjetividade somente a partir das marcas de enunciação, ou seja, quando um texto subjetivo está escrito em $1^{\mathrm{a}}$ pessoa e um texto objetivo e impessoal na $3^{\mathrm{a}}$ pessoa. Para esse lingüista, ela é a capacidade do locutor se propor como sujeito. Segundo Coracini (1991, p.92), Benveniste apresenta uma visão idealista de subjetividade, ao considerar "o 
sujeito (indivíduo) como centro, responsável consciente pela comunicação e, portanto, pela construção do significado".

Assim, atentar para a posição do locutor no texto tem o propósito de analisar as implicações das "modalidades implícitas ou explícitas" que camuflam a origem enunciativa, na medida em que dão a aparência de que é o fato ou o enunciado quem está dizendo e não propriamente o enunciador. Entendemos "modalidade" no sentido apontado por Coracini (1991, p.113): "é a expressão da subjetividade de um enunciador que assume com maior ou menor força o que enuncia, ora comprometendo-se, ora afastando-se”. Assim, para essa autora, a modalidade implícita além de esconder a aparente origem dos enunciados, exerce o papel de convencimento por meio da verdade enunciada; o que é comum no discurso científico.

Já a explícita aparece quando o locutor opina, justifica, emite juízos de valor, avalia, sugere, discute, prediz, hipotetiza, recomenda, ainda que não o faça tão declaradamente, utilizando expressões como "eu acredito que...". Mas ao fazer uso de afirmações do tipo "note-se que...", "percebe-se que...", "é possível verificar que..." está apenas sugerindo a sua presença, inclusive, procurando chamar a atenção do interlocutor. Dessa forma, acreditamos que ao evocá-la num texto, o locutor se situa na posição de quem quer dizer de si, apesar de não fazê-lo diretamente.

O enunciador representa as "perspectivas que o eu assume" no texto. A partir dessa função observaremos as tomadas de posições, as críticas feitas nos textos destes futuros professores pesquisados. Procuraremos identificar de que lugar eles falam, os sentidos que produzem e as subjetividades afloradas nesses textos. Estas singularidades apontam identificações que possibilitam compreender imagens, contradições, discursos anteriores que se entrelaçam e que sinalizam diferentes posições construídas na formação do sujeito professor.

Por fim a função autor tem relação com a interpretação, ela ocorre quando o sujeito se assume enquanto "produtor" da linguagem, responsabilizando-se pelo que diz e exercendo um modo de dizer padronizado e institucionalizado. Esta função será observada em relação à estrutura do texto, tendo em vista as orientações dadas. Enfatizaremos também os "deslizamentos de sentidos" praticados na escrita e também quanto à articulação teoria-prática, visto que esperávamos um relatório e um artigo descritivo-analítico, portanto uma leitura teórica da prática vivenciada. A 
opção por estes critérios deveu-se ao fato de entendermos que a organização textual bem como a relação entre a teoria e a prática podem revelar escolhas e incorporações que denotam a elaboração de um saber docente próprio e a enunciação de um discurso a respeito desse saber.

Uma vez apresentados os conceitos, passemos à contextualização do modo de produção dos textos.

\section{O CONTEXTO DE PRODUÇÃo DOS TEXTOS}

Considerando, portanto, a produção escrita um locus privilegiado de reconhecimento das manifestações de sentidos sobre ser e estar professor, investigamos aqui artigos e relatórios produzidos por quatro estagiários futuros professores.

Os relatórios foram elaborados na primeira fase do estágio quando fizeram o diagnóstico da escola, a partir da exploração de seu espaço físico, da leitura do projeto pedagógico e dos planos de ensino da disciplina e da observação de aulas de professores de Biologia. Foi sugerido que nessa etapa os estagiários coletassem e analisassem dados sobre a sala de aula: observar e analisar aulas no Ensino Médio de $1^{\mathrm{a}}, 2^{\mathrm{a}}$ e $3^{\mathrm{a}}$ séries de Biologia, quanto à interação professor-alunos, formas de exploração dos conteúdos, competências docente, atividades desenvolvidas, objetivos das aulas ministradas e utilização do material didático.

Já os artigos foram produzidos numa segunda etapa do estágio quando os licenciandos-estagiários ministraram aulas de Biologia no Ensino Médio e desenvolveram seus projetos de investigação sobre a própria prática. No caso, optaram por utilizar alguma estratégia didática, como jogos, aulas práticas, leitura, imagens ou mesmo vários recursos.

Foi solicitado que na elaboração do artigo destacassem a questão de investigação, os objetivos, as perspectivas teóricas, a metodologia empregada. Que relatassem e analisassem as próprias aulas ministradas, tendo em vista o referencial teórico adotado. Também o artigo deveria conter uma discussão apontando resultados, implicações para o ensino de Ciências e que por fim traçassem uma conclusão. Da mesma forma, o relatório recebeu recomendações sobre como deveria ser estruturado. 
Vale destacar que o gênero relatório já remete à ideia de impessoalidade, especialmente quando se trata de alunos do curso de Ciências Biológicas, vinculado à ideia de descrição de aulas práticas ou de experimentos de laboratórios, o que pode induzir o estagiário a apenas descrever o que foi visto, deixando os dados falarem por si. Isso pode ser confirmado com recurso ao próprio conceito corrente de relatório ao qual os alunos estavam habituados: "É a exposição escrita na qual se descrevem fatos verificados mediante pesquisas ou se historia a execução de serviços ou de experiências" (UFPR, 1996, p.28).

A descrição impessoal é, portanto, o modo enunciativo que caracteriza um relatório. Dessa forma, na tentativa de criar a possibilidade de um “desvio de padrão” em seus resultados, ou como afirma Maingueneau (2001 apud Furlanetto, 2005), embora haja gêneros extremamente ritualizados, certas variações são possíveis, instruímos os alunos que o produzissem flexibilizando os itens canônicos, bem como introduzindo outros não habituais, como título criativo e representativo da etapa de estágio que relatam; reflexão e adequação de subtítulos (por exemplo: "Materiais e métodos") de maneira que expressem não a objetificação, mas os sujeitos do estudo (alunos e professores); bem como adotar a perspectiva analítica em vez da descritiva, visando a articulação entre teoria estudada e a prática observada na escola. Tudo isso exemplificado a partir da leitura de relatórios produzidos nas mesmas circunstâncias em anos anteriores da disciplina.

Por sua vez o gênero artigo remete à ideia de cientificidade, de alguma inventividade, obtida pelo fato de que esses alunos, constantemente, realizam leitura de artigos científicos inéditos da área biológica, o que de antemão induz um modelo menos descritivo desta escrita, embora também ele esteja apoiado na mesma impessoalidade que caracteriza o relatório. Segundo as normas da Associação Brasileira de Normas Técnicas (ABNT), artigo científico é a "parte de uma publicação com autoria declarada, que apresenta e discute ideias, métodos, técnicas, processos e resultados nas diversas áreas do conhecimento”.

De modo que ambos, a princípio, prevalecendo as formas originais e habituais próprias do curso de origem dos estagiários, pouco possibilitariam ou mesmo contribuiriam para nosso objetivo. Assim, perguntamos: em que medida, inseridas as instruções que visam reconfiguração de ambos os gêneros, seriam eles adequados para promover a singularidade e a subjetividade 
de quem escreve? Em outras palavras, quais possibilidades de autoria eles ofereceriam? Para esboçar uma resposta, vejamos o que nos apontam os relatórios (escritos na fase de observação da escola) e os artigos (escritos na fase de docência). Os nomes dos estagiários são fictícios.

\section{A ANÁlise}

Relembrando mais uma vez que os relatórios foram produzidos na primeira etapa do estágio, ou seja, quando os licenciandos observaram a prática de algum professor de biologia e os artigos quando ministraram as aulas na escola, campo de estágio.

\section{a) Licenciando Arnoldo}

$\mathrm{Na}$ função locutor, em todo o artigo, Arnoldo não se referiu a si mesmo e escreveu utilizando expressões do tipo: foi possível..., foi notado..., foi trabalhado..., foi desenvolvido..., foi aplicado. Somente, em dois momentos, fez referência à sua própria atuação docente: o professor lia o texto.., ...permitiu a participação do professor na complementação... Já no relatório ele se autoreferenciou com o pronome "eu".

$\mathrm{Na}$ função enunciador este estagiário se posicionou no relatório utilizando expressões como, acho que a professora..., notei que esta estratégia..., não posso culpar... por conta das quais ele apresentou seu ponto de vista, concordando, discordando ou mesmo sugerindo como deveria ser feito. Em algumas passagens, predomina em sua memória a sua própria vivência como aluno, o que o fez abandonar seu posicionamento crítico por alguns instantes. Por exemplo, a disposição das carteiras faz o estagiário Arnoldo se recordar de seus tempos de aluno: A organização dos alunos na sala de aula me parece como qualquer outra, inclusive a minha quando fiz Ensino Médio. Nada de filas rígidas, alguns sentados em duplas, alguns de lado, etc. Também a prática da professora o faz compactuar com a prática dos estudantes: Não posso culpar os alunos pela conversa, não havia incentivo nenhum aos alunos. Assim, na função enunciador ocupa tanto a posição avaliativa, enquanto observador universitário, como uma posição compreensiva, enquanto aluno do ensino médio que já foi. 
No artigo, Arnoldo comenta principalmente sobre o trabalho que realizou com textos em sala de aula durante o estágio. Nele, destacou a atividade de leitura dos alunos, o que transcorreu com algumas dificuldades no encaminhamento das aulas. Identificou-as da seguinte maneira: os alunos não manifestam interesse por ler devido a uma certa 'preguiça' e falta de hábito...; ...os alunos apresentam problemas para interpretar e transmitir o que está escrito. Como se vê, as dificuldades foram atribuídas exclusivamente aos alunos. Quanto a si mesmo, relatou as alternativas que buscou para contornar a situação, ou seja, estabeleceu um tempo para os alunos lerem os textos durante a aula e esclareceu dúvidas, lendo juntamente com os estudantes. Dessa forma, identificou a dificuldade nos alunos e a sua superação, em si mesmo.

$\mathrm{Na}$ função autor, em artigo por ele intitulado Ensino de biologia: uma visão da utilização de leitura em sala de aula como ferramenta para ensinar ciência, fez referência a alguns autores no início, mas não retomados na análise dos dados. Assim, a relação teoria-prática solicitada, não foi devidamente articulada. Isso ficou evidente igualmente no tratamento que deu à sua questão de investigação, que visava interpretar a reação dos alunos frente às diferentes formas de trabalhar os textos, as maneiras de avaliar a interpretação do texto e como os alunos respondem à utilização da leitura. No entanto, suas conclusões foram bastante simplificadas, permanecendo no âmbito da atribuição de "falta de interesse" dos alunos.

A relação teoria-prática também foi mais uma vez insuficientemente equacionada. Por exemplo, quando fez um levantamento prévio visando conhecer o interesse dos alunos pela leitura, as finalidades desta, os veículos de informação mais utilizados, a ocorrência de leitura de reportagens da área científica, o que é recomendado pela literatura especializada, já que identificar as condições prévias dos alunos permite orientar com maior precisão a prática pedagógica. Os resultados deste levantamento, no entanto, apenas serviram para justificar o que presenciou nas aulas, ou seja, que a maioria dos alunos não gostava de ler, não lia efetivamente e não manifestava interesse. O que o levou a concluir que há a necessidade de desenvolver previamente o hábito de leitura no ensino fundamental para que haja uma familiarização gradativa. O que demonstra mais uma vez a prática da transferência de responsabilidades, isentando-se da iniciativa de promover a superação do déficit, tão comum entre professores. No entanto, ele destacou timidamente que as reportagens utilizadas como recurso didático despertaram a participação dos alunos nas aulas. 
Também no relatório, Arnoldo apesar de ter procurado identificar a prática docente observada a alguma tendência pedagógica por ele estudada, se referindo ao modelo tradicional de ensino, ao construtivismo, ao tecnicismo, o fez sem nenhum aprofundamento. Ainda que tenha citado vários autores durante o relatório, procurando fazer uma leitura teórica desta prática docente.

Quanto à estrutura do relatório, foi organizado com uma apresentação inicial justificando a contribuição da primeira etapa do estágio. A seguir traçou um perfil da professora observada e dos alunos, destacando, principalmente, suas características negativas. No item Análise das aulas fez uma introdução abordando a importância da utilização de diferentes estratégias de ensino e a ausência delas na escola em questão. Na descrição de cada uma das aulas assistidas relatou o conteúdo ministrado e alguns comentários sugerindo outras possibilidades de tratamento, essencialmente metodológico. No final comparou a situação da escola com uma desejável. $\mathrm{O}$ artigo seguiu os itens recomendados, mas não aprofundou na análise dos dados nem nas implicações e conclusão (as duas últimas estão juntas e resumidas a um parágrafo).

Comparando os textos produzidos por esse licenciando, podemos observar que na abrangência de seu relatório há mais posicionamentos, mais comentários avaliativos, desenvolve uma leitura um pouco mais teórica da prática docente do que no artigo. Neste ele apenas relatou o que fez, o que observou e as dificuldades enfrentadas, chegando a conclusões bastante simplificadas e inexpressivas.

\section{b) Licenciando Roger}

$\mathrm{Na}$ função locutor em nenhum momento do relatório Roger se refere a si mesmo, apenas descreve o que foi observado e faz alguns julgamentos sobre a prática da professora. Já o artigo foi escrito fazendo uso de um locutor ausente como: perguntas eram realizadas..., a aula iniciou.., discutiuse.., perguntou-se....

$\mathrm{Na}$ função enunciador tentou retratar a dinâmica da sala de aula, descrevendo os fatos intercalando atos da professora e dos alunos como se quisesse mostrar a ação de um e a reação do outro: solicita a cópia no caderno 
(...) com essa estratégia era visível o desinteresse dos alunos; (...)os alunos jogavam bolas de papel pela sala (...) ela demonstrava seu desinteresse em ensinar aos alunos dispersos (...); A professora solicitou que copiassem o conteúdo (...) muitos alunos reclamavam (...). Por meio dessa opção não se posiciona, apenas relata a circunstância.

No artigo, as aulas ministradas foram descritas sucintamente, contrastando sua atuação como professor problematizador com a apatia dos alunos em relação aos questionamentos. Assim, Roger concluiu que os estudantes analisados estavam acomodados ao processo de recepção passiva de informações própria do modelo tradicional reinante na escola.

Na função autor, quanto à articulação teoria-prática, seu artigo traz seis páginas de referencial teórico. Apesar desta extensão, o texto não apresenta qualquer tentativa de relação com o que foi desenvolvido e observado em sala de aula. O relatório não traz referência teórica, apenas descreve muito sucinta e superficialmente as aulas ministradas pela professora.

A estrutura do relatório não segue o que foi sugerido na disciplina Prática de Ensino nem os aspectos solicitados para serem observados são mencionados, o relato das aulas aborda apenas o que espontaneamente lhe chamou mais a atenção. Já seu artigo aborda os itens sugeridos, mas de maneira superficial na discussão dos resultados e conclusão.

Em síntese, no artigo, descreve mais detalhadamente a ação dele enquanto professor e a reação dos alunos, inclusive as dificuldades enfrentadas. Enquanto no relatório não há praticamente posicionamentos.

\section{c) Licenciando Brás}

$\mathrm{Na}$ função locutor, em seu relatório expõe-se ao fazer uma espécie de diário com expressões do tipo: $5^{a}$ feira - Liguei para o diretor requisitando uma vaga para estágio..; $2^{a}$ feira - Pela manhã falei com a Prof. $R$. ...; chego às 18:30h e fico esperando a professora $R$. Ela chega e me conta que o cronograma está atrasado..., $5^{a}$ feira - ... eu me ofereço para trazer material biológico...

$\mathrm{O}$ artigo que trata da investigação proposta por esse estagiário tinha por objetivo obter informações sobre: 
Influência do uso de recursos didáticos sobre a quantidade de atenção dispendida pelos alunos nas aulas de Biologia; Comparaşão entre os efeitos de diferentes tipos de recursos sobre a quantidade de atenção obtida.

Diante de tamanha objetividade, Brás se refere a si mesmo no artigo como 0 autor deste projeto, ele não descreve as aulas ministradas, apenas cita os conteúdos abordados a cada dia e o recurso adotado, não expressa nenhuma imagem de aluno ou de professor. Também faz a seguinte advertência, as conchusões apresentadas neste artigo são válidas apenas para este espaço amostral, sendo desaconselhável a extrapolação de tais dados, de forma indiscriminada, para outros espaços amostrais.

Como se pode notar, Brás apresenta em seu artigo uma visão restrita do ato de "prestar atenção", bastando, para ele, o aluno olhar quieto para o professor ou para o recurso didático.

Como enunciador este estagiário centra sua descrição nos alunos, comenta quantos estavam presentes no início, relata a chegada deles durante a aula, a troca de lugares entre eles, a acomodação nas carteiras, a disposição das carteiras na sala, perguntas feitas à professora, seus comentários sobre biologia, enfim, aspectos comportamentais. Pouco cita sobre a prática docente e muito menos faz julgamento sobre ela. Também há certa identificação com a professora, por exemplo, ao comentar: Aguardamos vários minutos até que todos terminassem os exercícios.

O licenciando Brás somente se posiciona no comentário geral que faz sobre a escola quando destaca que o livro didático foi o recurso mais utilizado nas aulas observadas, no qual ele vê o seguinte problema:

Se o professor se baseia no livro didático logo não são atingidos objetivos mais amplos como a relação com elementos do cotidiano que auxiliam na internalização e acomodação dos conhecimentos. Também não são trabalhados princípios básicos como o método investigativo científico e a expressão.

É perceptível o uso de uma terminologia piagetiana no texto de Brás, como internalização, acomodação e mesmo sua compreensão de autonomia, que, apesar de não explícita, perpassa pelas propostas construtivistas deste pensador. Como exposto abaixo: 
Imposição e autoridade são comportamentos comuns em alguns professores, isto porque os alunos freqüentemente estão desatentos. A autoridade e a imposição pode ser necessário, pois os jovens necessitam de limites, porém estes limites podem ser definidos pelos alunos mesmo.

Se Brás não estava imbuído dessa influência piagetiana, pelo menos ele se mostra filiado a um discurso escolanovista. Como pode ser notado em sua percepção sobre o funcionamento escolar:

A situação das escolas públicas é congruente com o conceito de escola democrática, aonde toda e qualquer pessoa pode usufruir. Outro ponto importante das escolas democráticas é a participação dos alunos, familiares e da população em geral na elaboração dos planejamentos de ensino.

Essas manifestações são as únicas que, poderia se dizer, procuram fazer alguma articulação teoria-prática no relatório. No artigo, as referências teóricas apresentadas no início do texto trazem esclarecimentos de um comentador a respeito do que alguns pensadores como Aristóteles, Santo Agostinho, Descartes, Leibniz e outros mais atuais pensaram sobre a atenção. Mas, na verdade, o que Brás desenvolveu em suas aulas foi utilizar recursos diferenciados a cada aula (transparências, vídeo, material biológico, cartazes, questionário, quadro negro) e a partir do número de alunos presentes ele contava quantos estavam dormindo ou conversando. Desse total, ele traçou uma porcentagem de atenção para cada recurso utilizado. Chegou inclusive a construir dois gráficos de formatos diferentes, mas representando a mesma relação (\% de atenção prestada $\mathrm{X}$ recursos didáticos).

A estrutura do relatório, principalmente no que tange à descrição das aulas, não segue o que foi solicitado, esse estagiário comenta aspectos bastante irrelevantes do que se espera que um futuro professor perceba e compreenda em relação ao espaço escolar. A mesma superficialidade é notada no artigo, iniciando pela proposta investigativa, passando pelo método e culminando na concepção do que seja a "atenção" dos alunos durante uma aula.

De modo geral, percebe-se nos textos desse licenciando uma incongruência de pensamentos, pois no relatório ele manifesta a filiação a um discurso escolanovista, defendendo a participação da comunidade escolar; a necessidade de desenvolver capacidades intelectuais, motoras e afetivas, além de se referir à aprendizagem por um viés piagetiano. Já no artigo, 
ele aborda a questão da atenção de uma maneira técnica e objetiva, sem estabelecer qualquer relação de natureza qualitativa.

\section{d) Licencianda Thalita}

$\mathrm{Na}$ posição enunciador, esta estagiária procura relatar a forma como a professora trabalhou em sala de aula, destacando assim as estratégias utilizadas e os conteúdos ministrados. O que mais lhe chamou a atenção foi se o assunto do dia estava relacionado ao cotidiano dos alunos e se ocorreu utilização de outro material além da apostila adotada. Esses dois aspectos, segundo sua visão, são o que possibilita maior ou menor participação dos alunos. Em todos os momentos em que ela discorda de algo realizado pela professora, Thalita emite sugestões de como poderia ser feito.

No artigo, ela faz descrição das aulas ministradas, comentando sobre o enfoque dado aos conteúdos e a contribuição na aprendizagem, para isso ela destaca as reações dos alunos.

Quanto à estrutura dos textos, Thalita segue o roteiro sugerido. No relatório destacam-se, principalmente, comentários sobre a competência docente e a interação professor-alunos. Para finalizá-lo faz uma síntese denominada Situação Atual do Colégio. Já o artigo está centrado no item $\mathrm{Me}$ todologia no qual detalha as aulas ministradas citando os recursos utilizados, o enfoque dado ao conteúdo e a reação dos alunos. Na Análise dos Dados apenas expõe duas tabelas quantificando as respostas de um questionário aplicado aos estudantes sobre as aulas e o trabalho docente da estagiária. Nos tópicos Resultados e Discussão e Conclusão Thalita apresenta explicações para essas percepções baseadas em observações do senso comum. Por exemplo:

A falta de resolução dos exercícios trazidos pelo livro didático foi citada por dois alunos, porém considero um aspecto que já era esperado pois, as aulas ministradas apresentaram estratégias de ensino diferentes da qual os alunos estão acostumados e algumas mudanças não são facilmente aceitas, no entanto, lembramos que toda a turma afirmou ter gostado das aulas.

Ao longo de seu relatório é perceptível vários posicionamentos do locutor que se assume como "eu". Por exemplo: as aulas me passaram a ideia de..., tive a impressão ..., pude perceber..., como pude constatar..., me pareceu muito 
boa.... Algumas vezes ela procura envolver o leitor em suas considerações, por exemplo, quando escreve, devemos levar em conta..., devemos lembrar das condições..., sabemos que a condição de nossos professores...

No artigo, essa estagiária se identifica em alguns momentos dizendo considero que..., em outro, ela se expressa aproximando da profissão que está para assumir, cabe a nós, futuros professores,.... Mas na maior parte o sujeito é indeterminado ou objetificado: Foi realizada..., As aulas..., O texto permitiu..., A estagiária foi....

Quanto à articulação teoria-prática, o artigo intitulado $A$ importância e a utilização de recursos diferentes do livro didático no processo de ensino-aprendizagem traz um referencial teórico bastante simplificado, baseado em quatro autores, um deles é uma entrevista retirada de revista não científica. Tal referencial não é considerado em sua análise. Para apurar a recepção de seu trabalho aplicou um questionário para os estudantes emitirem opiniões a respeito, sua conclusão está pautada nessas respostas, isto é, o interesse do professor em desenvolver aulas dinâmicas é o que faz a diferença. Já no relatório não há qualquer referência teórica.

Os textos produzidos por Thalita são bastante semelhantes, sua preocupação no diagnóstico, expresso no relatório, era com relação ao enfoque dado ao conteúdo e com a utilização de diferentes recursos didáticos, foi o que ela promoveu nas aulas que ministrou e foi o que prevaleceu em seu artigo.

\section{CONSIDERAÇÕES FINAIS}

\section{1) Quanto à posição locutor.}

Recordemos que, como dito no início, quando os licenciandos se autoreferenciam como "eu" ou "nós" ou utilizam a "modalidade explícita", por meio de recursos como nota-se que..; o que se percebe é...; sabe-se que..., denotam o propósito de opinar, sugerir, emitir julgamentos, manifestando subjetividade, exposição e comprometimento enquanto locutor com a asserção feita. Já quando o licenciando não se posiciona no texto, fazendo uso de voz passiva e ativa, transformando o objeto em sujeito do enunciado, perceptível em expressões do tipo: a aula foi..; o professor fez ...; a escola 
é... pode estar significando que ele não quis se comprometer com a função locutor, transferindo a asserção para um outro genérico, pondo em evidência o objeto de estudo e secundarizando sua opinião.

Segundo Coracini (1991), recorrer a essa forma parcialmente indefinida do sujeito, juntamente com a tentativa de envolver o leitor, equivale ao propósito de tornar o argumento incontestável. Isto pode ser também notado na ocorrência rara nos textos de expressões como épossível..., talvez..., parece que..., que admitem possíveis refutações à asserção. Juntos constroem a impressão de objetividade e conferem credibilidade e autoridade ao locutor.

Este fato pode ser reconhecido quanto à posição ocupada pelo sujeito estagiário, que se percebe como aquele que sabe (a imagem de si, um universitário atualizado) confrontado com a prática daquele que está defasado (a imagem do outro, o professor da escola). Assim, ocupando o lugar de aluno-licenciando, alimentado pela imagem de universitário-atualizado, acaba se distanciando e não se identificando com a posição-professor. Sobre isso, diz Orlandi (2003, p.39), "o lugar a partir do qual fala o sujeito é constitutivo do que ele diz" e faz.

Conforme observado até aqui, os gêneros textuais pouco oportunizaram aos estagiários auto-referirem como "eu" na posição locutor ou mesmo evocarem a "modalidade explícita", ainda que isso tenha ocorrido mais nos relatórios que nos artigos. Por conta disso, fica prejudicada a formação de professor autor, pois baseando-nos em Grigoleto (2005), um primeiro passo para isso seria a assunção de uma posição enunciativa própria, derivando daí a presença das marcas deste sujeito da enunciação expressas como singularidades, ou seja, que ele diga de si para que construa um conhecimento que lhe pertença.

Por isso vemos como problemática a questão do não envolvimento, ou mesmo do distanciamento dos licenciandos na escrita dos artigos, principalmente porque eles estavam tratando de suas próprias práticas e, no entanto, não ocorreu a implicação ou a inscrição mais profunda desses sujeitos produtores de linguagem e de conhecimento.

\section{2) Quanto à posiçãa enunciador}

Chama atenção nos textos o silêncio sobre a atuação docente dos licenciandos, procuramos explicá-lo recorrendo ao que Orlandi (1987) denomina 
"discurso da seriedade". Como dito acima, ocorreu um posicionamento de autoridade presumida por parte dos locutores dos textos, juntamente com a suposição de que no mundo acadêmico todo trabalho deva ser sério, ocasionando a incorporação de algumas regras de funcionamento desse discurso, por exemplo: o enunciador não se refere diretamente à própria seriedade, ainda que seja tolerável, é melhor falar da seriedade (ou falta dela) no trabalho do outro. Ou nas palavras de Orlandi (1987, p.267) "ao se erigir em figura de juiz, o enunciador desloca o foco da observação colocando-se, ele próprio, fora de discussão”.

Por este ângulo é compreensível que nos artigos tenham ocorrido poucas referências aos estagiários enquanto professores. Quando houve, se perceberam desenvolvendo ações bem sucedidas, como a de alguém buscando alternativas para envolver os alunos no processo de conhecer (artigo de Thalita), ou de alguém que controla o desenvolvimento das atividades na sala de aula (artigo de Arnoldo). As manifestações sobre o aluno foram sobre seu papel ativo nas aulas por eles ministradas (artigo de Roger e Arnoldo). Também descreveram dificuldades dos alunos em responder às ações planejadas (artigo de Arnoldo e Roger).

Os relatórios mais que os artigos possibilitaram a expressão de posicionamentos a favor ou contra a prática docente. Tal fato pode ser explicado, pela generalidade de abordagem que este gênero proporciona, enquanto nos relatórios a sala de aula foi relatada tendo em vista a atuação do professor, dos alunos, dos conteúdos, dos materiais didáticos; os artigos estavam direcionados para relatar a utilização de estratégias didáticas pelos licenciandos. Outro fator que influenciou cremos ser o fato de que ao observar a prática de outro docente, os licenciandos falam do lugar de aluno-estagiário, já nos artigos falavam do lugar de professor. E como diz Maingueneau (1989), o lugar de onde se fala determina a identidade de cada indivíduo e garante sua autoridade institucional. Essa posição de onde fala o sujeito seria o lugar encenado no discurso. E pelo que consta nesses textos, falar sobre o outro proporcionou mais expressividade que falar de si próprio.

Como já dito, no relatório, a função enunciador foi mais evidenciada, pois o artigo nem mesmo facilitou que os licenciandos se vissem no papel de professor. Em contribuição a essa função pode ser que o direcionamento do olhar do licenciando para alguns aspectos sobre o bairro, a escola e a sala de aula, como descrito no início foi determinador na elaboração do relatório 
para dois licenciandos, os outros dois não se remetem a estes aspectos, os textos de Brás e Roger, que, aliás, são bastante pobres quer de descrição quanto de análise e posicionamentos.

\section{3) Quanto à posição autor}

Tomando a articulação teoria-prática, foi perceptível que a maioria dos licenciandos não conseguiu articular o referencial teórico à prática desenvolvida. Até mesmo a escolha do referencial teórico se deu de maneira independente para a maioria dos estagiários, as disciplinas pedagógicas pouco influenciaram nessa escolha. Ao que cabe perguntar, os autores indicados nessas disciplinas têm possibilitado explicar a sala de aula?

Nos relatórios eles não fizeram uma leitura teórica a respeito da prática do professor observado na escola, mas ocorreu uma remissão teórica implícita (intertextualidade) em alguns pontos que mais lhes chamaram a atenção. Os principais aspectos incorporados em alguns textos, ainda que não se refiram diretamente a nenhuma teoria relacionada a eles foram:

a) A importância atribuída à interação professor-aluno no processo ensino-aprendizagem (observada nos relatórios de Thalita, Roger e Arnoldo) pode ter sido em função dos textos de Mortimer \& $\mathrm{Scott}^{1}$ e De Longhi ${ }^{2}$ lidos na disciplina Prática de Ensino e Estágio Supervisionado, nos quais são destacadas as interações discursivas como ferramenta na sala de aula. Também faz parte do estudo de De Longhi os tipos de perguntas que os professores fazem para os alunos, tendo elas as seguintes finalidades: controle do conhecimento já apropriado, indagar conceito ou compreensão de algo, sugerir resposta, provocar diversidade de opiniões. Os estagiários criticaram a ausência desse último tipo e reconheceram o pequeno resultado para a aprendizagem em utilizar apenas perguntas de controle ou de sugerir resposta.

b) Algumas idéias dos Parâmetros Curriculares Nacionais (PCN) aparecem principalmente quanto à abordagem dos conteúdos. Os estagiários

1. Mortmer E. \& Scott, P. Atividade discursiva nas salas de aula de ciências: uma ferramenta sociocultural para analisar e planejar o ensino. Investigações em Ensino de Ciências. v.7, n.3

2. De Longhi, A.L. El discurso Del profesor y Del alumno: análisis didático em clases de ciências. Enseñanza de las Ciencias, 2000, 18 (2), 201-216 
Thalita, Brás e Roger destacaram a relação dos conteúdos com o dia-a-dia do aluno, aspecto reforçado pelo PCN.

c) Os licenciandos atribuíram grande parte do ensino à utilização adequada de recursos didáticos, principalmente vídeo, jogos, textos, problemas e questionários, sendo eles responsáveis inclusive pelo comportamento e motivação dos alunos (relatórios de Arnoldo, Thalita e Roger). Fato perfeitamente compreensível, pois eles elaboraram propostas de ensino envolvendo tais recursos e a indisciplina é pensada em termos metodológicos no curso de Metodologia de Ensino (cursada anteriormente no $6^{\circ}$ período do curso de Ciências Biológicas). A escrita nas aulas de Biologia, quando referida nos artigos de Arnoldo e Roger parece que tinha em vista a possibilidade de interpretação pelos alunos do Ensino Médio, permitindo deslizamentos de sentidos e não apenas como repetição ou cópia das palavras do professor ou do material didático. Aspecto que também foi reforçado quando os licenciandos cursaram Metodologia de Ensino.

Assim, o gênero artigo possibilitou mais a articulação explícita da teoria com a prática, criando mais deslizamentos em função das solicitações da disciplina.

Quanto à estrutura dos textos produzidos, foi observado que em dois relatórios são descritos os aspectos solicitados para observação na sala de aula, dois deles se prendem a questões irrelevantes. No entanto, não foram perceptíveis re-significações nem deslizamentos ou deslocamentos na escrita desse gênero. O modo de enunciação mais comum foi o descritivo, por isso cabe aqui abordar o funcionamento discursivo da descrição. Para Orlandi et al (1989, p.113), “a descrição, porque se atarda sobre objetos e seres considerados em sua simultaneidade, visando os próprios processos como espetáculos (instauração do voyeurismo), parece suspender o curso do tempo e contribuir para instalar a narrativa no espaço". Desta forma, esse modo enunciativo "é de natureza contemplativa", diferente da narração que enfatiza a temporalidade.

Ainda segundo Orlandi et al (1989) a descrição insere o interlocutor (leitor) na construção da cena, no espaço, comprometendo-o, engajando-o. Este processo enunciativo é visto como uma atualização espaço-tempo do sujeito em seu discurso. Estas idéias nos fazem ver os textos dos licenciandos como acontecimentos que desejam dar a dimensão da sala de aula. Talvez esse fato explique a pouca ocorrência de deslizamentos de sentidos, princi- 
palmente nos relatórios. Já os artigos por centrarem num aspecto, o uso de alguma estratégia/recurso de ensino, facilitou um pouco mais a expressão de posicionamentos e criatividade na escrita. Lembrando que o conceito de criatividade remete à noção de polissemia, de instauração do novo.

Não discriminemos na análise o modo como as ideias dos autores (referencial teórico) apareceram nos textos, mas vale dizer que poucos utilizaram as aspas e quando o fizeram não referenciaram a página de onde foi retirada aquela citação. A maioria indicou que se tratavam de paráfrases. Fica como um aspecto que deva ser explorado na escrita dos futuros professores: a cópia e a elaboração.

Observamos o predomínio de algum tipo de levantamento de opinião ou de conhecimento dos alunos seguida da quantificação das respostas. Esses aspectos parecem indicar a importância atribuída à mensuração de resultados, ou seja, uma tentativa de apontar menos subjetividade nas conclusões.

Também se relaciona à busca da objetividade a ausência de um locutor explícito nos artigos, como comentado, em nenhum texto o estagiário fala em seu nome, ao contrário, ocorre remissão aos dados, isto é, "as aulas”, "os questionários”, "os alunos”, ou ocorre indeterminação do sujeito, remetendo ao "foi realizado...", "foi questionado...", "foi notado...".

Portanto, é preciso se questionar sobre o que se pretende ao adotar a escrita de gêneros acadêmicos. Se o objetivo é levar o licenciando a refletir sobre sua atuação enquanto professor, talvez estes não sejam os mais indicados, mesmo porque na maioria deles o estagiário nem se posicionou enquanto locutor do texto. Talvez seja o caso de se pensar em outros gêneros como: diários reflexivos, memoriais, estórias de vida, cartas, enfim, uma escrita que abarque manifestações de sentimentos, de dificuldades, de experiências já vividas, de expectativas etc. Que se produzam textos que levem o autor a se identificar com aquilo que escreve deixando ali suas marcas subjetivas e quem sabe ao ler e reler tais anotações possa perceber que há possibilidade e necessidade de mudança sempre. Como efeito, esperamos que futuramente ele se preocupe em desenvolver a escrita autoral de seus alunos.

Recebido em outubro de 2010 Aprovado em julho de 2013 E-mail: odissea@terra.com.br 


\section{REFERÊNCIAS BIBLIOGRÁFICAS}

Andrade, Ludmila T. 2004. Professores-leitores e sua formação: transformações discursivas de conbecimentos e de saberes. Belo Horizonte: Autêntica

Coracini, Maria José. 1991. Um fazer persuasivo: o discurso subjetivo da ciência. Campinas: Pontes.

Furlanetto, Maria M. 2005. Gênero do discurso como componente do arquivo em Dominique Maingueneau. In: Meurer, J.L.; Bonini, A.; Motta-Roth, D. Gêneros: teorias, métodos, debates. São Paulo: Parábola Editorial.

Grigoletto, Marisa. 2005. Do temor do texto ao texto próprio: desafios ao estudo da linguagem. Conferência apresentada no IV Seminário sobre Leitura e Produção no Ensino Superior durante o $15^{\circ}$ COLE (Congresso de Leitura), UNICAMP, Campinas.

Maingueneau, Dominique. 1989. Novas tendências em análise de discurso. Campinas: Pontes, p. 29-51.

Orlandi, Eni. 1987. A linguagem e seu funcionamento: as formas do discurso. São Paulo: Brasiliense.

; Guimarães, E.; Tarallo, F. 1989. Vozes e contrates: discurso na cidade e no campo. São Paulo: Cortez.

. 2000. Discurso e leitura. São Paulo: Cortez, 5 ed. . 2003. Análise de discurso: princípios e procedimentos. Campinas: Pontes, 5 ed.

Universidade Federal do Paraná. Biblioteca Central. Normas para apresentação de trabalhos: teses, dissertações e trabalhos acadêmicos. 5.ed. Curitiba: Ed. UFPR, 1996. 